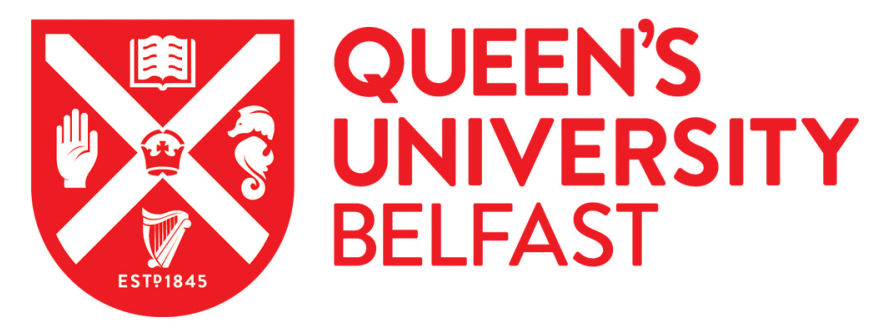

\title{
Future time perspective, positive emotions and student engagement: a longitudinal study
}

Denovan, A., Dagnall, N., Macaskill, A., \& Papageorgiou, K. (2020). Future time perspective, positive emotions and student engagement: a longitudinal study. Studies in Higher Education, 45(7), 1533-1546.

https://doi.org/10.1080/03075079.2019.1616168

\section{Published in:}

Studies in Higher Education

Document Version:

Peer reviewed version

Queen's University Belfast - Research Portal:

Link to publication record in Queen's University Belfast Research Portal

Publisher rights

( 2019 Society for Research into Higher Education. This work is made available online in accordance with the publisher's policies. Please refer to any applicable terms of use of the publisher.

\section{General rights}

Copyright for the publications made accessible via the Queen's University Belfast Research Portal is retained by the author(s) and / or other copyright owners and it is a condition of accessing these publications that users recognise and abide by the legal requirements associated with these rights.

Take down policy

The Research Portal is Queen's institutional repository that provides access to Queen's research output. Every effort has been made to ensure that content in the Research Portal does not infringe any person's rights, or applicable UK laws. If you discover content in the Research Portal that you believe breaches copyright or violates any law, please contact openaccess@qub.ac.uk. 


\title{
Future Time Perspective, Positive Emotions and Student Engagement: A Longitudinal Study
}

\author{
Andrew Denovan ${ }^{a}$, Neil Dagnall ${ }^{\mathrm{a}}$, Ann Macaskill ${ }^{\mathrm{b}}$, and Kostas Papageorgiou ${ }^{\mathrm{c}}$ \\ ${ }^{a}$ Department of Psychology, Manchester Metropolitan University, Manchester, UK; \\ ${ }^{b}$ Department of Psychology, Sheffield Hallam University, Sheffield, UK; ' Department of \\ Psychology, Queen's University Belfast, Belfast, UK \\ *Corresponding author: Andrew Denovan, Department of Psychology, Manchester \\ Metropolitan University, 53 Bonsall Street, Manchester, M15 6GX, UK. Email: \\ a.denovan@mmu.ac.uk
}

Author biographies:

Andrew Denovan is a Senior Lecturer in Psychology at Manchester Metropolitan University, a Chartered Psychologist with the British Psychological Society and a Fellow of the Higher Education Academy. His research interests include individual differences, positive psychology and the student experience in higher education.

Neil Dagnall is a Reader of Applied Cognitive Psychology at Manchester Metropolitan University. His research areas include memory, applied cognitive psychology and individual differences.

Ann Macaskill is a Professor of Health Psychology at Sheffield Hallam University, a Practitioner Health Psychologist (Health Professions Council) and a Principal Fellow of the Higher Education Academy. Her research interests include health and well-being, positive psychology and the student experience in higher education.

Kostas Papageorgiou is a Lecturer in Developmental Psychopathology at Queen's University Belfast and an Associate Professor in Personality Psychology at Tomsk State University. His research areas include individual differences in relation to educational performance, cognitive traits and resilience. 


\section{Future Time Perspective, Positive Emotions and Student Engagement:}

\section{A Longitudinal Study}

Student engagement is a key prognosticator of success, retention and perseverance in higher education. This study used structural equation modelling to evaluate a gain cycle of future time perspective (FTP), positive emotion and student engagement, derived from the broaden-and-build theory (BBT). A further objective was to examine changes within study variables over time. Participants were 217 UK undergraduates sampled at the beginning of the academic year, and the start of the second term. Analysis revealed that levels of positive emotion and engagement decreased, whereas FTP increased. At both time points, FTP predicted higher engagement, and engagement predicted greater positive emotion. Additionally, Time 1 positive emotion led to increased Time 2 FTP, engagement and positive emotion. This outcome was congruent with the 'build' hypothesis of BBT, suggesting that positive emotions enable the development of psychological resources. Relatedly, interventions designed to enhance FTP and positive emotion can facilitate student engagement and retention.

\section{Time 2 increased relative to time 1}

Keywords: broaden-and-build theory, future time perspective, positive emotions, student engagement, university students.

\section{Introduction}

Students' experience of the first year of university is an influential determinant of long-term participation in education (Zimitat 2004). Correspondingly, student engagement has emerged as the focus of research because it is central to persistence and retention (Horstmanshof and Zimitat 2007). Tinto (1993) suggests that engagement represents a synthesis of purposeful intentions and successful social and academic integration with the university environment. Relatedly, Kuh (2009) conceptualises student engagement as a combination of students' application to activities that are associated with the desired outcomes of university, and the means by which institutions facilitate student participation in these activities. 
Although, acknowledged widely as an important factor, conceptual consideration of student engagement is typically limited. Illustratively, Trowler (2010) conducted a review of student engagement literature and observed that studies often fail to define the term. This omission arises from the misguided assumption that there is consensual agreement about the meaning of student engagement. At an individual level, Astin (1984) and Horstmanshof and Zimitat (2007) view engagement as the quantity of energy and effort (physical and psychological) students dedicate to their university experience. This view was theoretically consistent with the current study.

Student engagement is widely acknowledged as a significant predictor of academic achievement and learner satisfaction in higher education (Kahu 2011). Research has consistently demonstrated that students who 'feel' engaged perform better educationally and enjoy studying more (Salanova et al. 2010). Relatedly, engagement is also a significant prognosticator of withdrawal from study (Crosling, Heagney, and Thomas 2009). Consequently, strategies for improving the student experience and increasing retention frequently centre on cultivating learner participation and commitment (Horstmanshof and Zimitat 2007).

\section{Future time perspective}

The concept of Time Perspective (TP) arose from interest in the impact of experience on present behaviour, future choices and the goals that individuals set themselves (see Zimbardo and Boyd 1999). TP comprises three temporal viewpoints (past, present and future) that act as cognitive frames for organising personal experiences; these provide a sense of order and coherence. TP acknowledges individual variations resulting from greater emphasis on particular time perceptions (Zimbardo and Boyd 1999). Research has demonstrated consistently that these influence judgments, actions and expectations (e.g., Boyd and Zimbardo 2005). Temporal frames afford useful insights into reliable individual differences that influence 
decision-making, future planning, confidence and actions (Zimbardo, Keough, and Boyd 1997).

Future Time Perspective (FTP), in contrast with other temporal orientations, is associated with adaptive self-regulatory study behaviour, including greater positive emotions towards studying, higher levels of determination and persistence (De Bilde, Vansteenkiste, and Lens 2011). Hence, FTP is highly relevant to educational settings because students with FTP are more likely to be committed to identifying and achieving prospective goals (Horstmanshof and Zimitat 2007). Indeed, Horstmanshof and Zimitat (2007) found that FTP was the strongest predictor of study engagement. Furthermore, future-oriented school students perform well across educational indices (i.e., obtain better grades, Zimbardo and Boyd 1999; manage time more efficiently, Peetsma, 1994; and attend classes, Harber, Zimbardo, and Boyd 2003). Thus, FTP provides the motivational resource needed to attain future goals. This explains why FTP is influential in determining the degree to which students engage with university study.

\section{Positive emotions}

Fredrickson (2001) suggests that positive emotions are associated with experienced well-being and widened thought-action repertoires. These arise from induced exploratory behaviours, which create learning opportunities, foster goal achievement, and build personal resources. These affirmative factors in turn produce higher levels of well-being. Although the precise mechanisms involved in these relationships are currently unknown, laboratory studies provide useful insights. Particularly, Fredrickson (2004) demonstrated that positive emotions, via the promotion of expanded thought and behaviour, reverse the adverse effects of experiencing negative emotions. Moreover, Frederickson et al. (2008), using a loving-kindness intervention, observed that daily increments in positive emotions helped to build personal resources (i.e., purpose in life and mindfulness) leading to higher life satisfaction. 
Experimental research indicates that positive emotions have a beneficial impact on academic learning, facilitating creative and holistic methods of problem solving as well as optimistic reliance on generalised structures of knowledge (Bless et al. 1996). In addition, positive activating emotions (e.g., enjoyment) correlate with academic motivation (Pekrun et al. 2002). Precise links between positive emotions and student engagement are less clear, but positive emotions are thought to facilitate approach behaviour, and in turn engagement (Ouweneel, LeBlanc, and Schaufeli 2011).

\section{Positive emotions, future time perspective and engagement}

Although interactions between FTP, positive emotions and student engagement remain largely unexplored, associated work indicates that these variables are positively interrelated. Explicitly, open-ended FTP (the view that one has a long and undetermined future) correlates with the positive emotional element of subjective well-being (SWB) (Coudin and Lima 2011). Furthermore, Ouweneel et al. (2011) reported a reciprocal enhancing relationship between positive emotions, personal resources and student engagement over a period of one month. Subsequently, Schaufeli and Van Rhenen (2006) confirmed that positive emotions directly predicted engagement in a cross-sectional study.

The broaden-and-build theory (BBT) (Fredrickson 2001) provides a useful framework for conceptualising these relationships. BBT theorises that experiencing positive emotions enables individuals to access a range of thoughts and possible actions. These facilitate the ability to respond cognitively and/or behaviourally to events. Over time, these strategies become enduring resources.

\section{The present study}

Furthering the work of Ouweneel et al. (2011), the current paper examined whether FTP (enhanced resources) and positive emotions facilitated student engagement. Specifically, the 'build' function of the BBT and previous literature informed construction of an empirical 
model that tested reciprocal relationships between FTP, positive emotions and student engagement. In this context, engagement was conceptualised as a measure of well-being. This was congruent with Ouweneel et al. (2011), who considered engagement as an active measure of well-being. Other work (e.g., Reschly et al. 2008) views engagement as an index of wellbeing. The focus on FTP derived from the observation that it represents a cognitivemotivational resource that has a beneficial psychological influence on educational outcomes (Horstmanshof and Zimitat 2007). Presently, there is a lack of confirmatory evidence regarding broaden-and-build relationships it was therefore important that this study conceptualised and assessed BBT in an educational setting.

Moreover, the present article by examining interactions between commitment to the future, positive emotion (positive affect; PA) and student engagement, aligned with Fredericks, Blumenfeld and Paris' (2004) observation that optimisation of the learning experience at university requires behavioural, cognitive and emotional engagement. Collectively, these factors measure personal allocation of psychological and behavioural resources to the academic experience (Horstmanshof and Zimitat 2007). This approach corresponds with the notion that intrinsic motivations, such as feelings of vigour, dedication to studying and absorption in academic activities predict higher levels of engagement (Schaufeli et al. 2002).

A further conceptual issue considered was the lack of consensual agreement about the direction of relationships between resources, positive emotions, and well-being. Originally, Fredrickson (2001) proposed that positive emotions initiated a building of resources, however, subsequent work proposes a more dynamic relationship, deriving from reverse causation and gain cycles. For instance, Xanthopoulou et al. (2009) reported a gain cycle of personal resources (e.g., optimism) and work engagement. Whereas, Llorens et al. (2007) observed that resources (e.g., self-efficacy) can precede as well as result from engagement. Engagement has been shown to act as a positive motivational-affective state, which, in addition to being 
informed by PA (Cacioppo, Gardner, and Berntson 1999), broadens and builds "by creating the urge to expand the self through learning and goal fulfilment" (Chen and Cooper 2014, 51). Accordingly, analysis of reciprocal relationships provided a suitable assessment of resource gain cycles, such as those proffered by the BBT (Wood et al. 2008). The proposed reciprocal model appears in Figure 1.

Figure 1 here

Since BBT is a process model based on change over time, variable assessment occurred at two time points separated by a three-month interval. Focusing on the beginning of each university term enabled comparisons to be made of student engagement throughout the students' first year of study; a critical period for determining degree progression (Denovan and Macaskill 2013; Zimitat 2004). Additionally, the initial transition phase is generally stressful (Denovan and Macaskill 2016), whereas the commencement of the second term is a period when students typically feel more settled, focused and engaged. Hence, the gap between these periods provided an opportunity for FTP and PA to interact. The researchers anticipated that FTP acts as a motivational variable increasing student engagement. Additionally, that engagement would enhance positive emotions. The use of two time points also allowed observation of this lagged effect.

Furthermore, using a longitudinal approach adds valuable complimentary evidence to previous BBT research conducted within educational settings. Historically, support for BBT in this context has emerged directly through cross-sectional work (e.g., Horstmanshof and Zimitat 2007; Schaufeli and Van Rhenen 2006), prior longitudinal investigations (although limited in quantity) (e.g., Llorens et al. 2007; Ouweneel et al. 2011), and indirectly via general laboratory studies (e.g., Fredrickson et al. 2008). Additional longitudinal work adds to preceding research by establishing the nature of effects and relationships (predictions, interactions) throughout the 
academic year, and extending the current literature. The focus on FTP via BBT using this type of design is a novel innovation.

Moreover, longitudinal assessment in a real-world setting (i.e., first year students adjusting to university) facilitates the scrutiny of variable direction naturally (Wood et al. 2008). Understanding whether FTP, engagement and PA reciprocally influence one another over time in this context is a critical consideration for the implementation of subsequent interventions. Appreciating the order of variable influence and factor interactions provides a firm indication of the elements to focus on in order to nurture engagement among students.

In summary, the present study tested BBT assumptions in relation to FTP and student engagement. Particularly, it assessed whether reciprocal relationships existed between FTP, engagement and PA over time. Consistent with previous literature this informed a conceptual model, which tested several specific outcomes. Firstly, the extent to which FTP at Time 1(T1) predicted engagement, and engagement PA. Secondly, the degree to which T1 scores positively predicted corresponding T2 scores. Finally, the model considered the presence of lagged effects. Specifically, the assumption that there was a reciprocal relationship between FTP, engagement and PA across time points. The study evaluated also, via mean comparisons whether student participation in university increased FTP, engagement and PA.

\section{Materials and Methods}

\section{Sample}

First year social science undergraduates from a post-92 UK university completed study measures at the beginning of the academic year (T1) and at the start of the second term, approximately three months later (T2). This time interval allowed sufficient time for well-being to change (Amati et al., 2010). In total, 217 (35 males and 182 females, mean age $=23.57, S D$ $=7.47$, range $=18$ to 53$)$ responded at both time points. There was a dropout rate of $18.7 \%$ 
from the initial sample of 267. Recruitment of participants occurred via laboratory classes and through email invitation across the university social sciences department.

\section{Measures}

\section{Positive emotion}

The positive affect subscale of the Positive and Negative Affectivity Schedule (Watson, Clark, and Tellegen 1988) assessed affirmative emotion. This comprises 10 items (e.g., determined, proud). Participants rate the extent to which they felt each emotion over the past month using a 5-point Likert scale, from 1 (very slightly or not at all) to 5 (extremely). High alpha reliability has been reported for the subscale $(\alpha=.90)$ (Watson et al. 1988) and it was high at both time points within this study (Time 1 PA $\alpha=.81$, Time 2 PA $\alpha=.83$ ).

\section{Future time perspective}

The Future subscale of the Zimbardo Time Perspective Inventory (Zimbardo and Boyd 1999) measured future time perspective. This consists of 13 items rated on a 5-point Likert scale ranging from very uncharacteristic (1) to very characteristic (5). The measure uses mean rather than total scores, thus scores range from 1 to 5 (Zimbardo and Boyd 1999). Reported internal consistency for the subscale is acceptable ( $\alpha=.77$; Kooij, Bal, and Kanfer 2014). In the current study reliability was acceptable at Time 1 (T1) and Time 2 (T2) (T1 $\alpha=.70, \mathrm{~T} 2 \alpha=.74)$.

\section{Student engagement}

The 14-item version of the Utrecht Work Engagement Scale for Students (UWES-S) (Schaufeli et al. 2002) assessed student engagement. The UWES-S consists of three subscales representing vigour, dedication, and absorption, rated on a 7-point Likert scale from never (0) to always (6). Reported internal consistency for subscales is good (vigour $\alpha=.74$, dedication $\alpha=.87$, absorption $\alpha=.84$ ) (Casuso-Holgado et al. 2013). In this study, alpha reliability was high at both time points for overall scores (T1 $\alpha=.93, \mathrm{~T} 2 \alpha=.92)$, and for the subscales (T1 
vigour $=.85, \mathrm{~T} 1$ dedication $=.90, \mathrm{~T} 1$ absorption $=.88 ; \mathrm{T} 2$ vigour $=.86, \mathrm{~T} 2$ dedication $=.86$, $\mathrm{T} 2$ absorption $=.86)$.

\section{Procedure}

Instructions directed participants to complete an online self-report measure. Prior to commencement, participants received an information sheet describing the purpose of the study and provided consent. Following completion of the measures, participants were debriefed. The procedure for Time 1 and Time 2 was identical. The University Research Ethics Committee approved the study.

\section{Data analysis}

The initial stage of analysis involved comparison of mean scores. Due to the inclusion of multiple measures assessed at two time intervals differences were evaluated using Multivariate ANOVA procedures. Specifically, Hotelling's $T^{2}$, which reduces the likelihood of making a Type I error when comparing means among potentially correlated outcomes (Tabachnick and Fidell 2001).

The next phase of analysis employed structural equation modelling (SEM), performed by AMOS 24, to test potential relationships among study variables. Following the recommended procedure of Anderson and Gerbing (1988), a measurement model preceded a test of structural models. Parcels of measured variables indicated latent variables of positive emotion (PA), future time perspective (FTP), and student engagement. Exploratory factor analysis (EFA) with oblique rotation examined each variable and determined the allocation of items to parcels. Item parcelling is effective for research scenarios with numerous measurement items because this increases the degrees of freedom and the statistical power of tested models (Coffman and MacCallum 2005).

Analysis assessed four models. Model 1, the stability model, assumed that each T1 variable leads to its respective T2 variable. Stability models test temporal constancy by 
estimating the stability coefficient between $\mathrm{T} 1$ and $\mathrm{T} 2$ without including variance from direct or indirect paths (Pitts, West, and Tein 1996). Model 2 was a synchronous model in which synchronous paths at T1 and T2 (e.g., T1 FTP $\rightarrow$ T1 engagement $\rightarrow$ T1 PA) were incorporated in addition to stability paths to test the stationarity assumption of the model (James, Mulaik, and Brett 1982). Model 3 was a causality model, which incorporated, in addition to the paths from Model 2, lagged paths from T1 FTP, engagement and PA to T2 FTP, engagement and PA. Model 4 was a reciprocal model that built on Model 3 and included additional lagged paths from T1 engagement to T2 and from T1 PA to T2 FTP and T2 engagement. According to Zapf, Dormann, and Frese (1996) the analysis of causal, reciprocal, and reverse relationships is justified in a latent modelling context when all variables are included at both time points.

The chi-square statistic, Comparative Fit Index (CFI), Tucker-Lewis Index (TLI), RootMean-Square Error of Approximation (RMSEA) and Standardised Root-Mean-Square Residual $($ SRMR) evaluated model fit. An acceptable model required CFI $>.90$, TLI $>.90$, SRMR $<.08$, and RMSEA $<.10$ (Browne and Cudeck 1993). For RMSEA the $90 \%$ confidence interval (CI) was included. Model comparison used Akaike's Information Criterion (AIC; Akaike 1974) in addition to chi-square difference. A lower AIC value indicated superior fit.

\section{Results}

\section{Preliminary analyses and comparison of FTP, engagement and PA scores over time}

Data screening checked for normality and outliers. Skewness and kurtosis ranges for all variables were between -2.0 and +2.0 (Byrne 2016). Following computation of z-scores, transformation of values above 3.29 or less than -3.29 to the next lowest or highest value occurred for each variable (Tabachnick and Fidell 2001). Accordingly, three univariate outliers underwent transformation. No multivariate outliers existed; data values were greater than .001 relative to Mahalonobis Distance and chi-square distribution (Tabachnick and Fidell 2001). 
A MANOVA Hotelling's $T^{2}$ test revealed a significant main effect of time on FTP, engagement and PA, $T^{2}=54.86, F(5,212)=11.01, p<.001, \eta_{\mathrm{p}}^{2}=.21$. Univariate $F$ tests indicated that FTP significantly increased from Time 1 to Time $2, F(1,216)=6.89, p=.009$, $\eta_{\mathrm{p}}{ }^{2}=.03$. Analysis failed to support the notion that student participation in university increased FTP, engagement and PA. Additional univariate tests indicated that there was a significant decrease from Time 1 to Time 2 in engagement, $F(1,216)=5.43, p=.021, \eta p 2=.03$; dedication, $F(1,216)=6.17, \mathrm{p}=.014, \eta \mathrm{p} 2=.03$; and PA, $F(1,216)=34.78, p<.001, \eta_{\mathrm{p}}^{2}=$ .14. Means and standard deviations alongside the univariate analyses appear in Table 1.

Table 1 here

\section{Summary}

These results indicated that levels of overall engagement, dedication and PA among the students decreased over the three-month timeframe. Only FTP increased over time.

\section{Intercorrelations and model evaluation}

Prior to analysis, an examination of data in relation to distributional assumptions of linearity, homoscedasticity, multivariate normality and multicollinearity was undertaken (Kline 2010). This revealed no issues with multicollinearity and all correlations were below .9 .

At $\mathrm{T} 1$ and $\mathrm{T} 2$, total engagement and engagement subscales were positively associated with FTP (Table 2). T1 total engagement and vigour were associated with T1 PA, and T2 PA was correlated with T2 total engagement and engagement subscales. Examining both time points revealed that $\mathrm{T} 1$ total engagement positively related with $\mathrm{T} 2 \mathrm{FTP}$, total engagement, dedication and PA. T1 PA was positively associated with T2 FTP, PA, total engagement and engagement subscales.

Table 2 here

EFA indicated that FTP possessed an underlying three-factor structure at both time points. PA had a single factor structure at T1 and T2. In order to include these single factors as 
indicators of latent variables (T1 PA and T2 PA) the variance of single factors was determined by multiplying scale variance with alpha reliability (Kline 2010). In the case of PA and FTP, EFA was necessary to determine indicator parcels. UWES-S subscales acted as indicators of student engagement. Established research supports the hierarchical factor structure of this measure (see Schaufeli et al. 2002). Factor loadings for the measured variables on the latent variables were all significant $(p<.001)$. The majority of indicators exhibited factor loadings above .60, meeting the strict factor loading requirements of Hair et al. (1998). Prior to model evaluation, examination of a measurement model in which all latent variables covaried was undertaken (Anderson and Gerbing 1988). Very good data-model fit was evident (see Table 3).

Table 3 presents the data-fit of each model. As can be seen, Model 2 reported significantly improved data-fit compared with Model $1, \chi^{2}$ difference $(4, N=217)=183.85, p$ $<.001$. Model 3 did not significantly improve on Model $2, \chi^{2}$ difference $(2, N=217)=3.05, p$ $=.216$. Model 4 (Figure 2) significantly improved data-fit compared with Model $3, \chi^{2}$ difference $(3, N=217)=24.24, p<.001$. Comparison of AIC values supported superior fit of Model 4 , as the AIC is 164.46, which is lower than the AIC for Model 3 (182.70), Model 2 (175.65) and Model 1 (351.50).

Table 3 here

Model 2 tested whether FTP positively related with engagement, and if engagement positively associated with PA at each time point. Model 2 additionally anticipated that T1 FTP would predict T2 FTP, T1 engagement would predict T2 engagement, and T1 PA would predict T2 PA. Significant positive paths emerged from T1 FTP to T1 engagement $(\beta=.85, p<.001)$, T1 engagement to T1 PA $(\beta=.24, p<.001)$, T2 FTP and T2 engagement $(\beta=.58, p<.001)$, and between T2 engagement and T2 PA $(\beta=.36, p<.001)$. Additionally, T1 PA significantly predicted T2 PA $(\beta=.36, p<.001)$. However, T1 engagement did not significantly predict T2 engagement $(\beta=.13, p=.088)$, and T1 FTP did not meaningfully predict T2 $\operatorname{FTP}(\beta=.15, p=$ 
.123). Model 3 tested the notion that positive lagged effects existed concerning T1 FTP to T2 engagement and T2 PA, and T1 engagement to T2 PA. However, no lagged effects were present.

Model 4 assumed the existence of a reciprocal relationship between variables in addition to the causality model predictions. Specifically, that T1 engagement had a positive lagged effect on T2 FTP, and T1 PA had a positive lagged effect on T2 FTP and T2 engagement. Inspection of the structural paths of Model 4 revealed that T1 PA had a significant positive lagged effect on T2 PA $(\beta=.33, p<.001)$, T2 FTP $(\beta=.20, p=.012)$ and on T2 engagement $(\beta=.26, p<.001)$. However, T1 engagement did not have a significant lagged effect on T2 FTP $(\beta=.10, p=.71)$. Similar to Model 3, a significant lagged effect from T1 FTP to T2 engagement and T2 PA, and from T1 engagement to T2 PA did not emerge. The results support the notion that FTP predicts both engagement and PA, and that engagement predicts PA at both time points. Furthermore, T1 PA predicted T2 PA. Overall, Model 4 revealed that T1 PA influenced FTP, engagement, and PA at T2, thus partially supporting a reciprocal relationship.

Figure 2 here

\section{Summary}

These results suggested that at each time point, the level of FTP predicted higher engagement, and the level of engagement predicted greater PA among the students. In addition, PA at T1 influenced higher PA at T2, signifying a positive relationship over time. However, contrary to expectations, FTP and engagement at T1 did not predict subsequent levels of FTP and engagement.

Moreover, positive lagged effects were not present, meaning that a student's level of FTP did not influence their engagement, and that a student's level of engagement did not 
influence their PA over the three-month period. However, some reverse causality existed in the form of PA (at T1) influencing subsequent FTP and engagement (at T2).

\section{Discussion}

This paper examined how relationships between attitudes, traits and behaviours influenced student engagement. The predictive relationships in the structural model indicated that Future Time Perspective (FTP) predicted engagement at both time points. This finding was consistent with Horstmanshof and Zimitat (2007), who identified FTP as an important psychological influence on student engagement. Specifically, FTP effects engagement via the use of deep learning strategies and a greater degree of academic application. This manifests as positive actions, attitudes and behaviours, such as the desire to work consistently, increased levels of motivation, and the ability to seek support from teaching staff.

In agreement with Horstmanshof and Zimitat (2007), strengthening of FTP has the potential to lead to an increase in study engagement and prevent attrition, in this instance within university students. Similarly, engagement predicted increased levels of positive affect (PA) at each time point. This was anticipated, given that individuals with higher levels of engagement display not only a tendency to experience positive emotions (Schaufeli and Van Rhenen 2006), but to experience positive emotions that are high in activation, including enthusiasm, joy, and interest (Langelaan et al. 2006).

The current study evidenced a gain relationship between positive emotions with FTP and engagement over time. It is possible, therefore, that these activating emotions in turn are responsible for mobilising students into action and influence a greater degree of FTP and sustained engagement. Indeed, the results for positive emotion provided support for the BBT. Particularly the 'build hypothesis', which posits that people will enhance their personal 
resources (in this instance FTP) as a function of experiencing positive emotions, leading to increased well-being (in this instance engagement) over time.

It is possible, however, that an alternative explanation exists in the form of PA acting as an antecedent of, or at least co-occurring with FTP. Indeed, Kooij, Kanfer, Betts, and Rudolph (2018) found that affectivity co-occurs with FTP when predicting a range of psychological outcomes (e.g., happiness and anxiety). In this context, affectivity represents a dimension of FTP, which references the valence of anticipated future events (see Brothers, Chui, Diehl, and Pruchno 2014). However, a lack of research has examined this possibility. Consequently, Kooij et al. (2014) contend that a more effective measure of FTP is required. Explicitly, one that builds on standardised scales (such as the ZTPI) and incorporates affectivity. Future research accordingly should evaluate co-occurrence of affectivity. This is necessary given Kooij et al. (2014) ascertain that affectivity, in the context of FTP, is distinct from general notions of affect.

Although FTP increased at the mean level and positive emotion predicted this, in contrast to Ouweneel et al. (2012) no reciprocal gain relationship was evident. Greater specificity may provide an explanation. Pertinently, research indicates that both trait-like features and individual differences in the goals people possess determine the cognitivemotivational effects of FTP. Lens et al. (2012) established that the content (what people are working towards) and depth (distance into the future) of goals have motivational consequences for the effects of FTP. A focus on goals could have accounted for greater variance when considering FTP as a predictor over time.

In addition, consideration of goals may have added further clarity regarding the low association between T1 and T2 FTP. It is possible that students possessed different goals, orientations and intentions at each respective time point, and variations in the academic year may confound FTP scores. Therefore, a qualitative study focusing on how different time points 
affect future orientation could prove beneficial by providing insights into discordant FTP scores, and the potentially beneficial effects that PA may have in sustaining high FTP. Indeed, Denovan and Macaskill (2013) found that students changed and adjusted over time in relation to factors including academic focus and expectations of university study. The use of a qualitative approach engendered rich insight into the underlying reasons for these adjustments.

The results suggest overall that although engagement and positive emotion levels decreased over time at the mean level, that FTP, engagement and positive emotion increase as a function of initial level of positive emotion. Positive emotion in this context has a catalytic effect. Hence, from a practical viewpoint, the development of research on the role of positive emotion in relation to FTP and other resources can have significant implications for improving engagement and retention amongst undergraduates. Such progress is pertinent given the relatively high levels of attrition in first year (HESA 2016).

Accordingly, in addition to creating supportive environments for undergraduates to thrive, universities should find ways to develop FTP and positive emotion as mechanisms to prevent early withdrawal from university. For example, place a greater emphasis on encouraging students to consider their future goals relative to university study through structured activities (e.g., skills assessment and planning for academic success) (Horstmanshof and Zimitat 2007).

Furthermore, PA is to an extent malleable (Reschly et al. 2008). Research indicates that at a school-level promoting students' skills can increase positive emotion (Seligman et al. 2009). Illustratively, through the Penn Resiliency Program, which uses relatively straightforward methods (e.g., 'Three Good Things' exercise). These when taught to schoolbased learners increase the student's ability to experience PA, even amidst difficult circumstances (Seligman et al. 2009). Integrating similar principles within higher education 
has the potential to equip students with skills that develop and sustain their PA, even when confronted with uncontrollable stresses and problems that typically undermine engagement.

This study also considered mean changes over time. FTP increased from T1 to T2. However, engagement and PA decreased. Furthermore, scores on the engagement scales declined. In the case of dedication, this reduction was significant. This tentatively suggests that a drop in dedication was mainly responsible for the overall reduction in engagement.

Previous research reports a link between lowered student engagement and increased dropout rates. Indeed, high first year attrition is a major concern in the UK (HESA 2016), United States and Australia (Horstmanshof and Zimitat 2007). Within this study, the researchers assumed that volunteers would possess relatively high levels of engagement. Observed reductions in engagement and a dropout rate at $\mathrm{T} 2$ of $18.7 \%$ confounded this notion. These findings reflect the complex nature of student engagement. This concurs with Denovan and Macaskill (2016), who reported a decrease in engagement and positive emotion over the first year of university study.

This may occur because university level study necessitates a movement to autonomous learning, which students struggle to negotiate (Macaskill 2013). The timing of data collection in this study coincided with the transition from student-centred to autonomous learning. Specifically, it spanned the period from school/college, through university induction to undergraduate study. This is a challenging time for students because they encounter new delivery styles, different educational demands and novel content (Denovan and Macaskill 2013). Future work should examine whether engagement increases subsequently, particularly its development throughout year one and the middle and later stages of a degree programme.

\section{Limitations and future research}

This study relied on the use of self-report measures, which possess limitations including common method variance. In this context, although the results accord with previous research, 
it would have been beneficial to include objective criterion measures such as study grades (Brown et al. 2008). Additionally, there was a lack of consideration of goals to supplement FTP. Another issue relates to the generalisability of the results because assessment occurred within a single faculty of a HE institution. Subsequent work should examine the extent to which findings generalise beyond the present context. Additionally, the present sample was mainly female $(83.8 \%)$. Thus, it would be useful to assess whether gender differences exist in the 'build' pattern in future work. It was not possible to do this within the present study due to sample size restraints (specifically, the small subsample of men, $n=35$ ).

Finally, future work could extend the research beyond the first year of university study. Although this was necessary for assessing the most sensitive time relative to student engagement and retention (Tinto 1993), a comparison with later time points and/or students from later years of a university degree course would potentially have enriched the findings, revealing whether students become more engaged in later years and how this relates to FTP and positive emotion. Research indicates, for example, that level of engagement measured at the start of university can predict later degree success (Svanum and Bigatti 2009).

\section{Conclusion}

This study demonstrated moderate to strong predictive relationships among FTP, engagement and positive emotion (PA) at single time points. Moreover, a gain cycle existed over time relating to the effects of PA on later FTP, engagement and PA. These findings provide support for the 'build' hypothesis of the BBT and further understanding of the dynamic relationship that exists among FTP, engagement and PA. At odds with these results, mean levels of engagement and PA decreased. Therefore, interventions that focus on and develop positive emotion in addition to FTP are likely to facilitate student engagement. 


\section{References}

Akaike, H. 1974. "A new look at the statistical model identification." IEEE Transactions on Automatic Control 19(6): 716-723. doi:10.1109/TAC.1974.1100705

Anderson, J.C., and D.W. Gerbing. 1988. "Structural equation modelling in practice: A review and recommended two-step approach.” Psychological Bulletin 103(3): 411423. doi:10.1037/0033-2909.103.3.411

Astin, A.W. 1984. "Student involvement: A developmental theory for higher education." Journal of College Student Personnel 25(4): 297-308.

Bless, H., G.L. Clore, N. Schwarz, V. Golisano, C. Rabe, and M. Wölk. 1996. "Mood and the use of scripts: Does a happy mood really lead to mindlessness?" Journal of Personality and Social Psychology 71(4): 665-679.

Boyd, J.N., and P.G. Zimbardo. 2005. “Time Perspective, Health, and Risk Taking.” In Understanding Behavior in the Context of Time: Theory, Research, and Application, ed. A. Strathman and J. Joireman, 85-107. Mahwah: Lawrence Erlbaum.

Brothers, A., H. Chui, M. Diehl, and R. Pruchno. 2014. "Measuring future time perspective across adulthood: Development and evaluation of a brief multidimensional questionnaire.” The Gerontologist 54(6): 1075-1088. doi:10.1093/geront/gnu076

Brown, S.D., S. Tramayne, D. Hoxha, K. Telander, X. Fan, and R.W. Lent. 2008. "Social cognitive predictors of college students' academic performance and persistence: A 
meta-analytic path analysis." Journal of Vocational Behavior 72(3): 298-308. doi:10.1016/j.jvb.2007.09.003

Browne, M.W. and R. Cudeck. 1993. “Alternative ways of assessing model fit.” In Testing structural equation models, ed. K.A. Bollen and J.S. Long, 136-162. Beverly Hills: Sage.

Byrne, B.M. 2016. Structural equation modeling with AMOS: Basic concepts, applications, and programming. 3rd ed. New York: Routledge.

Cacioppo, J.T., W.L. Gardner, and G.G. Berntson. 1999. "The affect system has parallel and integrative processing components: Form follows function.” Journal of personality and Social Psychology 76(5): 839- 855. doi:10.1037/0022-3514.76.5.839

Casuso-Holgado, M.J., A.I. Cuesta-Vargas, N. Moreno-Morales, M.T. Labajos-Manzanares, F.J. Barón-López, and M. Vega-Cuesta. 2013. “The association between academic engagement and achievement in health sciences students.” BMC Medical Education 13(1): 33. doi:10.1186/1472-6920-13-33

Chen, P.Y., and C.L. Cooper, C.L., eds. 2014. Wellbeing: a complete reference guide, work and wellbeing. Vol. 3. Chichester: John Wiley \& Sons.

Coffman, D.L., and R.C. MacCallum. 2005. "Using parcels to convert path analysis models into latent variable models." Multivariate Behavioral Research 40(2): 235-259. doi:10.1207/s15327906mbr4002_4

Coudin, G., and M.L. Lima. 2011. "Being well as time goes by: Future time perspective and well-being.” International Journal of Psychology \& Psychological Therapy 11(2): 219-232.

Crosling, G., M. Heagney, and L. Thomas. 2009. “Improving student retention in higher education: Improving teaching and learning." Australian Universities' Review 51(2): 9-18. 
De Bilde, J., M. Vansteenkiste, and W. Lens. 2011. "Understanding the association between future time perspective and self-regulated learning through the lens of selfdetermination theory." Learning and Instruction 21(3): 332-344. doi:10.1016/j.learninstruc.2010.03.002

Denovan, A., and Macaskill, A. 2013. “An interpretative phenomenological analysis of stress and coping in first year undergraduates." British Educational Research Journal 39(6): 1002-1024. doi:10.1002/berj.3019

Denovan, A., and A. Macaskill. 2016. "Stress and subjective well-being among first year UK undergraduate students: A longitudinal study.” Journal of Happiness Studies 18(2): 505-525. doi:10.1007/s10902-016-9736-y

Fredricks, J.A., P.C. Blumenfeld, and A.H. Paris. 2004. "School Engagement: Potential of the Concept, State of the Evidence.” Review of Educational Research 74(1): 59-109. doi:10.3102/00346543074001059

Fredrickson, B.L. 2001. "The role of positive emotions in positive psychology: The broadenand-build theory of positive emotions." American Psychologist 56(3): 218-226. doi:10.1037/0003-066X.56.3.218

Fredrickson, B.L. 2004. "The broaden-and-build theory of positive emotions." Philosophical Transactions of the Royal Society B: Biological Sciences 359(1449): 1367-1378. doi:10.1098/rstb.2004.1512

Fredrickson, B.L., M.A. Cohn, K.A. Coffey, J. Pek, and S.M. Finkel. 2008. “Open hearts build lives: positive emotions, induced through loving-kindness meditation, build consequential personal resources." Journal of personality and social psychology 95(5): 1045-1062. doi:10.1037/a0013262 
Harber, K.D., P.G. Zimbardo, and J.N. Boyd. 2003. "Participant self-selection biases as a function of individual differences in time perspective." Basic and Applied Social Psychology 25(3): 255-264. doi:10.1207/S15324834BASP2503_08

Hair, J.F., R.E. Anderson, R.L. Tatham, and W.C. Black. 1998. Multivariate data analysis. 5th ed. Upper Saddle River: Prentice hall.

HESA. 2016. “UK Performance Indicators.” Accessed February 32018. https://www.hesa.ac.uk/data-and-analysis/performance-indicators/summary

Horstmanshof, L., and C. Zimitat. 2007. "Future time orientation predicts academic engagement among first-year university students.” British Journal of Educational Psychology 77(3): 703-718. doi:10.1348/000709906X160778

James, L.R., S.A. Mulaik, and J.M. Brett. 1982. Causal analysis: Assumptions, models and data. Beverly Hills: Sage.

Kline, R.B. 2010. Principles and practice of structural equation modelling. 3rd ed. New York: Guilford Press.

Kooij, D.T., P.M. Bal, and R. Kanfer. 2014. "Future time perspective and promotion focus as determinants of intraindividual change in work motivation." Psychology and Aging 29(2): 319-328. doi:10.1037/a0036768

Kooij, D.T., R. Kanfer, M. Betts, and C.W. Rudolph. 2018. "Future time perspective: A systematic review and meta-analysis." Journal of Applied Psychology 103(8): 867893. doi:10.1037/ap10000306

Kahu, E.R. 2011. "Framing student engagement in higher education." Studies in Higher Education 38(5): 758-773. doi:10.1080/03075079.2011.598505

Kuh, G.D. 2009. "What Student Affairs Professionals Need to Know about Student Engagement." Journal of College Student Development 50(6): 683-706. doi:10.1353/csd.0.0099 
Lang, F.R., and L.L. Carstensen. 2002. "Time counts: Future time perspective, goals, and social relationships.” Psychology and Aging 17(1): 125-139. doi:10.1037/08827974.17.1.125

Langelaan, S., A.B. Bakker, W.B. Schaufeli, W. van Rhenen, and L.J. van Doornen. 2006. "Do burned-out and work-engaged employees differ in the functioning of the hypothalamic-pituitary-adrenal axis?" Scandinavian journal of work, environment \& health 32(5): 339-348.

Lens, W., M.P. Paixao, D. Herrera, and A. Grobler. 2012. "Future time perspective as a motivational variable: Content and extension of future goals affect the quantity and quality of motivation." Japanese Psychological Research 54(3): 321-333. doi:10.1111/j.1468-5884.2012.00520.x

Llorens, S., W.B. Schaufeli, A. Bakker, and M. Salanova. 2007. "Does a positive gain spiral of resources, efficacy beliefs and engagement exist?" Computers in Human Behavior 23(1): 825-841. doi:10.1016/j.chb.2004.11.012

Macaskill, A. 2013. "The mental health of university students in the United Kingdom." British Journal of Guidance \& Counselling 41(4): 426-441. doi:10.1080/03069885.2012.743110

Ouweneel, E., P.M. Le Blanc, and W.B. Schaufeli. 2011. "Flourishing students: A longitudinal study on positive emotions, personal resources, and study engagement." Journal of Positive Psychology 6(2): 142-153. doi:10.1080/17439760.2011.558847

Peetsma, T. 1994. "Toekomstperspectief als voorspeller van inzet voor school. (Future time perspective as a predictor of school engagement)." Tijdschrift Voor Onderwijsonderzoek 19(4): 331-342. 
Pekrun, R., T. Goetz, W. Titz, and R.P. Perry. 2002. “Academic emotions in students' selfregulated learning and achievement: A program of qualitative and quantitative research.” Educational psychologist 37(2): 91-105. doi:10.1207/S15326985EP3702_4

Pitts, S.C., S.G. West, and J.Y. Tein. 1996. "Longitudinal measurement models in evaluation research: Examining stability and change. Evaluation and Program Planning” 19(4): 333-350. doi:10.1016/S0149-7189(96)00027-4

Reschly, A.L., E.S. Huebner, J.J. Appleton, and S. Antaramian. 2008. "Engagement as flourishing: The contribution of positive emotions and coping to adolescents' engagement at school and with learning." Psychology in the Schools 45(5): 419-431. doi:10.1002/pits.20306

Salanova, M., W.B. Schaufeli, I. Martínez, and E. Breso. 2010. "How obstacles and facilitators predict academic performance: The mediating role of study burnout and engagement." Anxiety, Stress, and Coping 23(1): 53-70. doi:10.1080/10615800802609965

Schaufeli, W.B., I. Martínez, A. Marques Pinto, M. Salanova, and A.B. Bakker. 2002. Burnout and engagement in university students: a cross national study. "Journal of Cross Cultural Psychology”33(5): 464-481. doi:10.1177/0022022102033005003

Schaufeli, W.B., and W. Van Rhenen. 2006. “Over de rol van positieve en negatieve emoties bij het welbevinden van managers: Een studie met de Job-related Affective Wellbeing Scale (JAWS) [About the role of positive and negative emotions in managers' well-being: A study using the Job-related Affective Well-being Scale (JAWS)].” Gedrag and Organisatie 19(4): 223-244.

Seligman, M.E., R.M. Ernst, J. Gillham, K. Reivich, and M. Linkins. 2009. “Positive education: Positive psychology and classroom interventions." Oxford Review of Education 35(3): 293-311. doi:10.1080/03054980902934563 
Svanum, S., and S.M. Bigatti. 2009. “Academic course engagement during one semester forecasts college success: Engaged students are more likely to earn a degree, do it faster, and do it better." Journal of College Student Development 50(1): 120-132. doi:10.1353/csd.0.0055

Tabachnick, B.G. and L.S. Fidell. 2001. Using multivariate statistics. Boston: Allyn and Bacon.

Tinto, V. 1993. Leaving college: Rethinking the causes and cures of student attrition. 2nd ed. Chicago: University of Chicago Press.

Trowler, P. 2010. Student engagement literature review. York: The Higher Education Academy.

Watson, D., L.A. Clark, and A. Tellegen. 1988. "Development and validation of brief measures of positive and negative affect: The PANAS scales.” Journal of Personality and Social Psychology 54(6): 1063-1070. doi:10.1037/0022-3514.54.6.1063

Wood, A.M., J. Maltby, R. Gillett, P.A. Linley, and S. Joseph. 2008. "The role of gratitude in the development of social support, stress, and depression: Two longitudinal studies." Journal of Research in Personality 42(4): 854-871. doi:10.1016/j.jrp.2007.11.003

Xanthopoulou, D., A.B. Bakker, E. Demerouti, and W.B. Schaufeli. 2009. "Reciprocal relationships between job resources, personal resources, and work engagement.” Journal of Vocational Behavior 74(3): 235-244. doi:10.1016/j.jvb.2008.11.003

Zapf, D., C. Dormann, and M. Frese. 1996. “Longitudinal studies in organizational stress research: A review of the literature with reference to methodological issues." Journal of Occupational Health Psychology 1(2): 145-169. doi:10.1037/1076-8998.1.2.145

Zimbardo, P.G., and J.N. Boyd. 1999. "Putting time in perspective: A valid, reliable, individual-differences metric." Journal of Personality and Social Psychology 77(6): 1271-1288. doi:10.1037/0022-3514.77.6.1271 
Zimbardo, P.G., K.A. Keough, and J.N. Boyd. 1997. "Present time perspective as a predictor of risky driving." Personality and Individual Differences 23(6): 1007-1023. doi:10.1016/S0191-8869(97)00113-X

Zimitat, C. (2004). "The first year university experience frames students' later university experiences." Paper presented at ANZARE Annual Conference, Wellington, November.

Table 1. Means, standard deviations and univariate analyses for future time perspective, engagement, engagement subscales, and positive affect at Time 1 and Time 2

\begin{tabular}{lccccl}
\hline & \multicolumn{2}{c}{ Time 1 } & \multicolumn{2}{c}{ Time 2 } & \\
\hline Variable & Mean & $S D$ & Mean & SD & Significance of $F$ \\
\hline $\begin{array}{l}\text { Future Time } \\
\text { Perspective }\end{array}$ & 3.36 & .38 & 3.47 & .52 & $p=.009$ \\
Engagement & & & & & \\
Vigour & 49.94 & 11.60 & 47.38 & 13.69 & $p=.021$ \\
Dedication & 15.05 & 4.97 & 14.41 & 5.49 & $p=.157(\mathrm{~ns})$ \\
Absorption & 21.21 & 5.04 & 20.03 & 5.36 & $p=.014$ \\
Positive Affect & 13.67 & 4.11 & 12.94 & 5.11 & $p=.081(\mathrm{~ns})$ \\
\hline
\end{tabular}

Note. $\mathrm{ns}=$ non-significant 
Table 2. Descriptive statistics and correlations

\begin{tabular}{|c|c|c|c|c|c|c|c|c|c|c|c|c|c|c|}
\hline Variable & Mean & $S D$ & 1 & 2 & 3 & 4 & 5 & 6 & 7 & 8 & 9 & 10 & 11 & 12 \\
\hline $\begin{array}{l}\text { 1. T1 Future Time } \\
\text { Perspective }\end{array}$ & 3.36 & .38 & & $.58 * *$ & $.57 * *$ & $.42 * *$ & $.45^{* *}$ & $.15^{*}$ & .09 & .04 & .08 & -.01 & .04 & .12 \\
\hline 2. T1 Total engagement & 50.53 & 12.33 & & & $.87 * *$ & $.82 * *$ & $.76^{* *}$ & $.20 * *$ & $.17^{*}$ & $.19 *$ & $.15^{*}$ & $.18^{* *}$ & $.16^{*}$ & $.13 *$ \\
\hline 3. T1 Vigour & 15.23 & 5.25 & & & & $.57 * *$ & $.54 * *$ & $.25^{* *}$ & $.15^{*}$ & $.23 * *$ & $.20^{* *}$ & $.20^{* *}$ & $.20 * *$ & $.15^{*}$ \\
\hline 4. T1 Dedication & 21.48 & 5.07 & & & & & $.40^{* *}$ & .10 & .10 & .07 & .01 & .10 & .08 & .08 \\
\hline 5. T1 Absorption & 13.81 & 4.32 & & & & & & $.14^{*}$ & $.19 * *$ & $.17^{*}$ & $.18^{* *}$ & $.15^{*}$ & .11 & .09 \\
\hline 6. T1 Positive Affect & 31.31 & 7.95 & & & & & & & $.15^{*}$ & $.38^{* *}$ & $.33^{* *}$ & $.31^{* *}$ & $.33 * *$ & $.48 * *$ \\
\hline $\begin{array}{l}\text { 7. T2 Future Time } \\
\text { Perspective }\end{array}$ & 3.47 & .52 & & & & & & & & $.41^{* *}$ & $.41 * *$ & $.29 * *$ & $.35^{* *}$ & $.24 * *$ \\
\hline 8. T2 Total engagement & 47.38 & 13.69 & & & & & & & & & $.87 * *$ & $.83^{* *}$ & $.87 * *$ & $.44 * *$ \\
\hline 9. T2 Vigour & 14.41 & 5.49 & & & & & & & & & & $.56^{* *}$ & $.67 * *$ & $.43 * *$ \\
\hline 10. T2 Dedication & 20.03 & 5.36 & & & & & & & & & & & $.59 * *$ & $.32 * *$ \\
\hline 11. T2 Absorption & 12.94 & 5.11 & & & & & & & & & & & & $.37 * *$ \\
\hline 12. T2 Positive Affect & 27.56 & 7.32 & & & & & & & & & & & & \\
\hline
\end{tabular}

Note. $\mathrm{T} 1=$ Time $1 ; \mathrm{T} 2=$ Time $2 ;{ }^{*} p<.05 ;{ }^{*} p<.001$ 
Table 3. Fit indices of the five models

\begin{tabular}{llllllll}
\hline Model & $\chi^{2}$ & $d f$ & CFI & TLI & SRMR & $\begin{array}{l}\text { RMSEA } \\
(90 \% \mathrm{CI})\end{array}$ & Chi-square difference \\
& & & & & & $.04(.01-.06)$ & \\
\hline Measurement model & 80.65 & 64 & .98 & .97 & .04 & $.12(.10-.13)$ & \\
Model 1 (stability) & $291.50^{* *}$ & 75 & .73 & .67 & .16 & $.05(.03-.07)$ & M1-M2 $=183.85^{* *}$ \\
Model 2 (synchronous) & $107.65^{*}$ & 71 & .95 & .94 & .05 & .05 & M2-M3 $=3.05$ \\
Model 3 (causality) & $110.70^{*}$ & 69 & .95 & .93 & .06 & $.05(.03-.07)$ & M3-M4 $=24.24 * *$ \\
Model 4 (reciprocal) & $86.46^{*}$ & 66 & .98 & .97 & .04 & $.04(.01-.06)$ & M3 \\
\hline
\end{tabular}

Note. $\chi 2$ = chi-square goodness-of-fit statistic; $d f=$ degrees of freedom; CFI = Comparative Fit Index; SRMR = Standardised Root-Mean-Square Residual; RMSEA = Root-Mean-Square Error of Approximation; AIC = Akaike Information Criterion; * $\chi 2$ significant at $p<.05, * * \chi 2$ significant at $p<.001$ 